\title{
Behavioral responses of zebrafish depend on the type of threatening chemical cues
}

\author{
Murilo S. Abreu $^{1} \cdot$ Ana Cristina V. Giacomini ${ }^{2} \cdot$ Darlan Gusso $^{2} \cdot$ Gessi Koakoski $^{1} \cdot$ Thiago A. Oliveira $^{1} \cdot$ \\ Alessandra Marqueze ${ }^{5}$. Rodrigo Egydio Barreto ${ }^{4}$ Leonardo J. G. Barcellos $^{1,2,3}$
}

Received: 16 June 2016 / Revised: 16 October 2016 / Accepted: 17 October 2016 / Published online: 24 October 2016

(C) Springer-Verlag Berlin Heidelberg 2016

\begin{abstract}
In fish, defensive reactions are induced by different chemical cues that emanate from sense-related stresses [physical, chemical, and visual (visual contact with predator)] or food stresses (acute fasting and chronic food restriction). Using a shuttle box with a two-chamber unmixed laminar flow that allowed fish to remain or flee from a chemical cue, we showed that the avoidance response depended on the type of the chemical cue. We show that zebrafish (Danio rerio) retreated from water conditioned with chemical cues released by chemically or physically stressed fish and acutely fasted fish, but not from water with cues from fish experiencing visual contact with predatory fish or fish suffering from chronic food restriction. Our data reinforced the hypothesis that fish use a combination of information and the context of the situation to determine their evasion strategy.
\end{abstract}

Keywords Defensive behavior - Chemical cues · Attraction $\cdot$ Aversion $\cdot$ Zebrafish

Leonardo J. G. Barcellos

lbarcellos@upf.br

1 Programa de Pós-Graduação em Farmacologia, Universidade Federal de Santa Maria (UFSM), Santa Maria, RS, Brazil

2 Universidade de Passo Fundo (UPF), Passo Fundo, RS, Brazil

3 Programa de Pós-Graduação em Bioexperimentação, Universidade de Passo Fundo (UPF), Passo Fundo, RS, Brazil

4 Department of Physiology, Institute of Biosciences of Botucatu, Caunesp, Unesp, Botucau, SP, Brazil

5 Centro Universitário La Salle-Unilasalle, Programa de Pós-Graduação em Avaliação de Impactos Ambientais, Canoas, RS, Brazil

\section{Introduction}

The structural complexity and variations of habitat are known to have significant effects on populations and can shape behavior, morphology, and life history traits (Brown and Braithwaite 2005). An animal's perception of habitat, environment, and its variations is important, and allows it to be equipped to deal with chemical cues of danger that might arise in the environment. Perception of chemical cues can potentially increase survival, allowing individuals to avoid a threatening situation. This is a well-known phenomenon related to prey-predator systems (Chivers and Smith 1998; Korpi and Wisenden 2001).

In fish, several types of chemical cues have been reported as released and perceived by conspecifics leading to defensive responses. These responses include changes in behavior (Chivers and Smith 1998) and induction of stress responses (Pfeiffer and Lamour 1976; Rehnberg et al. 1987; Rehnberg and Schreck 1987; Toa et al. 2004; Barreto et al. 2010; Sanches et al. 2015). One type of threatening chemical cues is called disturbance chemical cues, which are defined as cues released in the water by non-injured fish in stressful contexts (Barcellos et al. 2011), including nonlethal prey-predator encounters (Jordão and Volpato 2000; Barcellos et al. 2014).

Several questions regarding communication via disturbance chemical cues remain unexplored. One such question is: does the stressor that lead to the release of a disturbance chemical cue modulate behavioral responses of the receiver fish? Based on observations of other types of threatening chemical cues, we hypothesized that different forms of chemical communication, such as exposure to water conditioned with chemical cues released by chemically or physically stressed fish or cues from fish experiencing acute fasting or chronic food restriction, can cause stress in receiver 
fish and change in behavior, such as avoidance of conditioned water. Fish may respond by immobility (freezing) or dramatically reducing swimming (slowing), or may evade the cue source (Schwarze et al. 2013; Sabet et al. 2015).

A new methodological paradigm allows us to address this question. The use of a two-chamber shuttle box with unmixed laminar flow in the chambers allows fish to remain or flee from a chemical cue (Readman et al. 2013; Abreu et al. 2016). Thus, to answer our question, we investigated zebrafish (Danio rerio) behavior in response to exposure to disturbance chemical cues produced by conspecifics experiencing various stressors. We used this species as an animal model because they respond to disturbance chemical cues (Hussain et al. 2013) and have been used as an animal model for research for over three decades in various disciplines, including physiology, toxicology, genetics, embryology, metabolism, oncology, neuroscience, cardiovascular studies, and the study of neurodegenerative diseases (Barbazuk et al. 2000; Mueller et al. 2004; Alsop and Vijayan 2009; Egan et al. 2009; Howe et al. 2013).

\section{Materials and methods}

\section{Subjects}

The stock population of 200 adult, wild-type zebrafish of the short-fin (SF) strain, weighing $0.65 \pm 0.1 \mathrm{~g}$, was housed in a tank. One hundred fish were placed in ten tanks (ten fish per tank) for the preparation of conditional water and the other half was used for the analysis of individual perception in the apparatus (Fig. 1). All fish were supplied constant aeration and biological filtering under a natural photoperiod (approximately, $14 \mathrm{~h}$ light:10 h dark). The water was maintained under the following conditions: temperature $=27 \pm 1{ }^{\circ} \mathrm{C} ; \mathrm{pH}=7.0 \pm 0.2$; dissolved oxygen $=6.3 \pm 0.5 \mathrm{mg} \mathrm{L}^{-1}$; total ammonia $=0.01 \mathrm{mg} \mathrm{L}^{-1}$; total hardness $=6 \mathrm{mg} \mathrm{L}^{-1}$, and alkalinity $=22 \mathrm{mg} \mathrm{L}^{-1}$ $\mathrm{CaCO} 3$.

\section{Experimental strategy}

We conducted a two-choice experiment, where the tested fish could choose between clean or conditioned water (with a test disturbance substance). We used an experimental apparatus (Fig. 1a) that consisted of an acrylic tank with two separated compartments of unmixed laminar flows of $2 \mathrm{~L} \mathrm{~min}^{-1}$ (Abreu et al. 2016), and fish could move between these compartments. Confirmation (via gentian violet dye) of unmixed laminar flux for all types of conditioned water is shown in Fig. 1 b.

\section{Physical stress, chemical stress, and visual contact with a predator}

The goal of this study was to determine if fish decide to evade conditioned water (physical stress, chemical stress, visual contact with a predator-detailed in Table 1) and preferentially seek clean water. Fish were individually tested by placing one into an experimental apparatus, distributed into five treatments (ten fish treatment ${ }^{-1}$; see Table 1).

\section{Food deprivation stress}

The goal of this study was to determine if fish decided to evade conditioned water (cues from fish experiencing acute fasting, chronic food restriction, or normal nutrition; detailed in Table 2) and preferentially seek clean water. Fish were individually tested by placing one fish into the
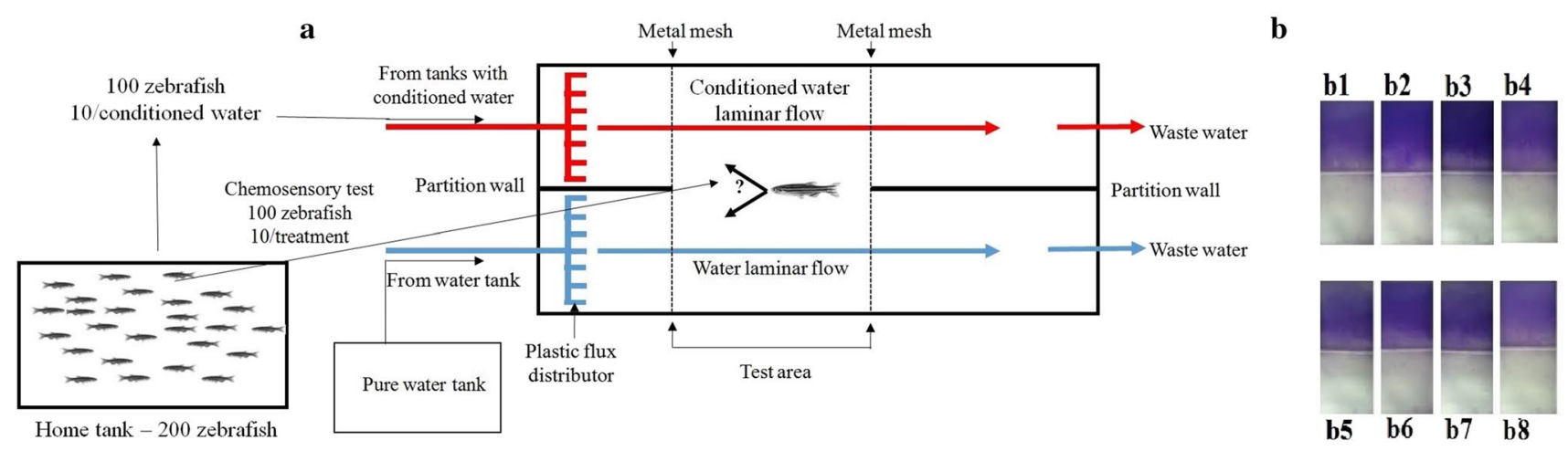

Fig. 1 Experimental setup. a Schematic representation of the test chamber. b Photographic confirmation of the maintenance of the laminar flow. Images show the stability of laminar flow during dosing. Each compound was stained with a violet indicator to visually follow the progression of the compound. $b 1$ Negative control, $b 2$ positive control (pH 3), b3 physical stress, $b 4$ chemical stress, $b 5$ contact visual predator, $b 6$ fish in normal nutritional status, $b 7$ fish experiencing acute fasting, and $b 8$ fish experiencing chronic food restriction 
Table 1 Different forms of stress (physical stress, chemical stress, visual contact predator)
Table 2 Different forms of food deprivation stress

\begin{tabular}{|c|c|c|}
\hline Group & Experimental protocol & References \\
\hline Control & Water & Abreu et al. (2016) \\
\hline $\mathrm{pH} 3$ & Water with $\mathrm{pH} 3$ & Abreu et al. (2016) \\
\hline Physical stress & $\begin{array}{l}\text { Fish chased with a net for } 2 \mathrm{~min} \text {; after } \\
15 \text { min the water was introduced into the } \\
\text { apparatus* }\end{array}$ & - \\
\hline Chemical stress & $\begin{array}{l}\text { Fish exposed to } \mathrm{pH} \text { of } 5 \text { for } 15 \mathrm{~min} \text {; after- } \\
\text { ward the water was introduced into the } \\
\text { apparatus* }\end{array}$ & - \\
\hline $\begin{array}{l}\text { Visual of predator display [predator- } \\
\text { tiger oscar (Astronotus ocellatus)] }\end{array}$ & $\begin{array}{l}\text { Fish viewed the predator for } 15 \mathrm{~min} \text {; } \\
\text { afterward the water was introduced into } \\
\text { the apparatus* }\end{array}$ & - \\
\hline
\end{tabular}

* Aquarium with ten fish $10 \mathrm{~L}^{-1}$ for conditioning stimulus-containing water

\begin{tabular}{lll}
\hline Group & Experimental protocol & References \\
\hline Control & Water & Abreu et al. (2016) \\
pH 3 & Water with pH 3 & Abreu et al. (2016) \\
Fish in a normal nutritional status & Water fish fed twice daily* & \\
Fish experiencing acute fasting & Water from food-deprived fish for 48 $\mathrm{h}^{*}$ & - \\
Fish experiencing chronic food restriction & Water fish fed once a week for 30 days* & - \\
\hline
\end{tabular}

* Aquarium with ten fish $10 \mathrm{~L}^{-1}$ for conditioning stimulus-containing water experimental apparatus, distributed in five treatments (ten fish treatment ${ }^{-1}$; see Table 2).

\section{Experimental procedures}

Individual fish were transferred from the holding tank to the recording apparatus and were acclimated for $150 \mathrm{~s}$. Next, a continuous dose of the test compound was injected into one of the compartments for $150 \mathrm{~s}$. Clean water and conditioned water were alternated between the right and left section of the apparatus among tests to avoid any possible laterality bias caused by a fish preferring to stay on either the left or right side. All fish examined during the test enter in the conditioned side, which guarantee contact with the conditioned water. Thus, thereafter the absence of fish permanency on the conditioned side indicated avoidance of the treatment. After each test, the apparatus was thoroughly washed with water to remove any residual test substance. The location and activity of fish with access to both the treated and untreated sections were recorded with a video camera for the entirety of the experimental period (Abreu et al. 2016). The video camera was positioned directly above the apparatus. The analysis of video recordings of individual fish was performed using AnyMaze ${ }^{\circledR}$ video monitoring system (Stoelting, CO, USA), for both the acclimatization periods (approximately $150 \mathrm{~s}$ ) and $150 \mathrm{~s}$ of exposure. For assessment, the following parameters were collected per test (for clean water and treatments), number of crossings, total distance traveled, mean speed swimming, absolute turn angle, and rotations.

\section{Statistics}

The homogeneity of variance and normality were assessed by Hartley and Kolmogorov-Smirnov tests, respectively. Wilcoxon matched-pairs test was conducted to compare subjects' permanency time between compartments. The total number of crossing between compartments, total distance traveled, mean speed swimming, absolute turn angle, and rotations were compared by Kruskal-Wallis test followed by Dunn's post hoc test. Differences were considered statistically significant at $p<0.05$.

\section{Results}

\section{Physical stress, chemical stress, and visual contact with a predator}

Figure 2 shows the time spent in the conditioned and clean lanes, and the pre-trial analysis (initial $150 \mathrm{~s}$ ) before the influx of cues, indicating that attraction or aversion began at the moment of conditioned water influx. In the control (with clean water in both lanes), no preference was detected ( $p=0.6953)$, whereas in the positive control, zebrafish showed a clear aversion to $\mathrm{pH} 3(p=0.001)$. Fish perceived water conditioned to a $\mathrm{pH}$ of $3(p=0.001)$, disturbance cues from chemically stressed fish $(p=0.0039)$, and disturbance cues from physically stressed fish $(p=0.0313)$ as aversive stimuli. Attraction or aversion was not detected for any other treatment. 


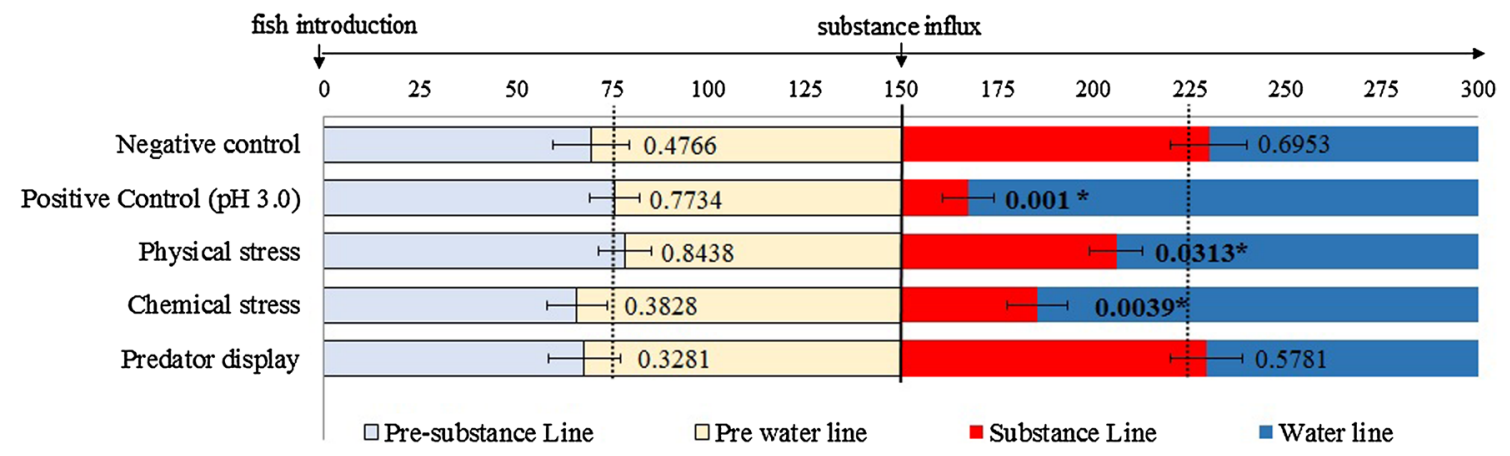

Fig. 2 Time spent (s) in the substance or water lane during the 150 -s pre-substance influx and during the $150 \mathrm{~s}$ of substance exposure test. The data are expressed as the mean \pm SEM for each lane. The means were compared by Wilcoxon matched-pairs signed-ranks test. $p$ values are depicted following each bar

Table 3 Locomotor activity of zebrafish exposed to different forms of stress (physical stress, chemical stress, visual contact with predator)

\begin{tabular}{lcccr}
\hline Substance & Distance $(\mathrm{m})$ & Mean speed $\left(\mathrm{m} \mathrm{s}^{-1}\right)$ & Absolute turn angle $\left({ }^{\circ}\right)$ & Rotations \\
\hline Control & $13.109 \pm 2.103$ & $0.0874 \pm 0.014031$ & $35008 \pm 2471$ & $28.8 \pm 6.06$ \\
pH 3 & $\mathbf{8 . 7 2 2} \pm \mathbf{0 . 7 9 2}$ & $\mathbf{0 . 0 5 8} \pm \mathbf{0 . 0 0 5 2}$ & $32599 \pm 1219$ & $18.9 \pm 2.15$ \\
Physical stress & $13.170 \pm 3.091$ & $0.087 \pm 0.0206$ & $33067 \pm 3328$ & $24.42 \pm 6.2$ \\
Chemical stress & $10.351 \pm 0.996$ & $0.069 \pm 0.0066$ & $\mathbf{2 8 1 0 7} \pm \mathbf{0 1 0}$ & $23.55 \pm 2.58$ \\
Fish acutely stressed (predator display) & $12.928 \pm 1147$ & $0.086 \pm 0.0075$ & $28990 \pm 1910$ & $21.85 \pm 2.84$
\end{tabular}

Data expressed as mean \pm SEM. Kruskal-Wallis followed by Dunn's post hoc test. Distance travelled $(K=11.12 ; p=0.0252)$, mean speed $(K=11.02 ; p=0.0263)$, absolute turn angle $(K=9.735 ; p=0.0451)$, and rotations $(K=2.387 ; p=0.6649)$. Significant effects are given in bold

Table 4 Number of crossings of zebrafish exposed to different forms of stress (physical stress, chemical stress, visual contact with predator)

\begin{tabular}{lcc}
\hline Substance & \multicolumn{2}{l}{ Number of crossings } \\
\cline { 2 - 3 } & 0-150 s (before substance influx) & 151-300 s (during substance influx) \\
\hline Control & $17.6 \pm 3.78$ & $30.1 \pm 6.21$ \\
pH 3 & $19.125 \pm 3.94$ & $\mathbf{1 2 . 0 9} \pm \mathbf{3 . 7}$ \\
Physical stress & $22.375 \pm 2.73$ & $30.71 \pm 10.73$ \\
Chemical stress & $20.25 \pm 2.51$ & $17.44 \pm 3.27$ \\
Fish acutely stressed (predator display) & $25.85 \pm 4.9$ & $27.55 \pm 4.11$
\end{tabular}

Data expressed as mean \pm SEM. Kruskal-Wallis followed by Dunn's post hoc test. Number of crossing 151-300 s (during substance influx) $(K=11.98 ; p=0.0175)$. Significant effect is given in bold

Distance traveled, mean speed (pH 3, Table 3), and absolute turn angle exhibited differences (chemical stress, Table 3). The number of crossings were different for the fish in the $\mathrm{pH} 3$ conditioned water (Table 4).

\section{Food deprivation stress}

Figure 3 shows the control (with clean water in both lanes), in which no preference was detected $(p=0.6953)$, whereas in the positive control, zebrafish showed a clear aversion to $\mathrm{pH} 3$ water $(p=0.0010)$. Fish perceived only the water conditioned by fish fasted for $48 \mathrm{~h}(p=0.0020)$ as an aversive stimulus. Attraction or aversion was not detected for any other treatment.

No significant differences were detected for distance traveled, mean speed ( $\mathrm{pH} \mathrm{3}$, Table 5), absolute turn angle, and rotations (Table 5).The number of crossings was significantly different for the $\mathrm{pH} 3$ positive control (Table 6).

\section{Discussion}

Herein, we showed that zebrafish avoided water conditioned with chemical cues released by chemically or 


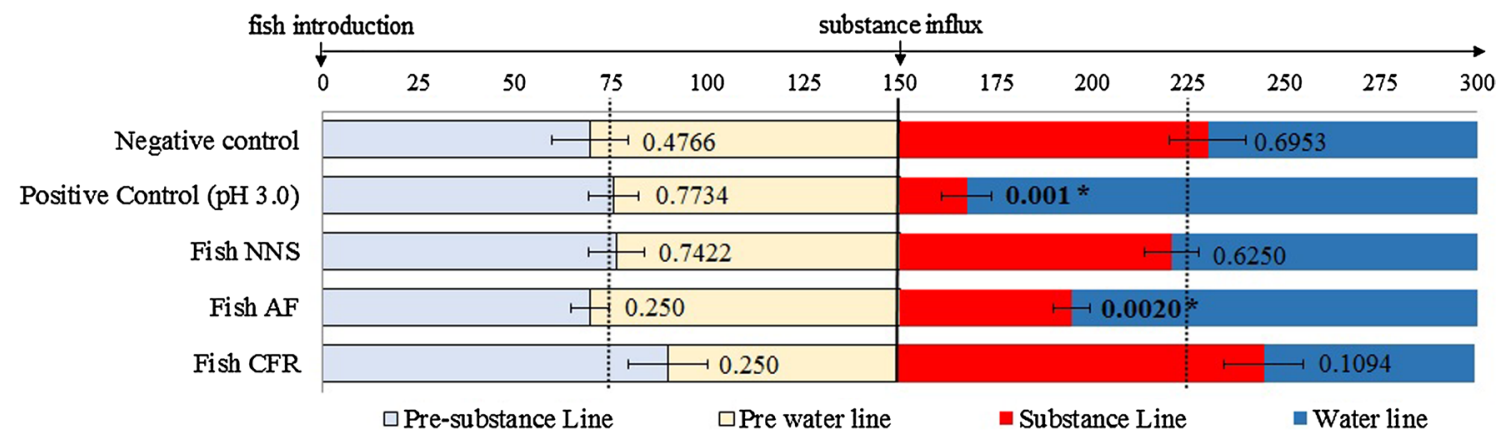

Fig. 3 Time spent (s) in the treated or water lane during the 150-s pre-substance influx and during the $150 \mathrm{~s}$ of substance exposure test. The data are expressed as mean \pm SEM for each lane. The means were compared by Wilcoxon matched-pairs signed-ranks test. $p$ val- ues are depicted following each bar. Fish NNS fish in normal nutritional status; Fish AF fish experiencing an acute fast; Fish CRF fish experiencing chronic food restriction

Table 5 Locomotor activity of zebrafish exposed to different forms of food deprivation stress

\begin{tabular}{lccrr}
\hline Substance & Distance $(\mathrm{m})$ & Mean speed $(\mathrm{m} / \mathrm{s})$ & Absolute turn angle $\left(^{\circ}\right)$ & Rotations $^{\circ}$ \\
\hline Control & $11.655 \pm 0.893$ & $0.087 \pm 0.014$ & $35509 \pm 2705$ & $30.22 \pm .59$ \\
pH 3 & $\mathbf{7 . 6 1 6} \pm \mathbf{0 . 5 4 5}$ & $\mathbf{0 . 0 5 3 7} \pm \mathbf{0 . 0 0 2 8}$ & $32611 \pm 1285$ & $18.4 \pm 2.31$ \\
Fish in a normal nutritional status & $12.229 \pm 1005$ & $0.0815 \pm 0.0067$ & $34738 \pm 1658$ & $19.9 \pm 1.51$ \\
Fish after acute fasting & $14.318 \pm 1134$ & $0.0954 \pm 0.0075$ & $31224 \pm 1214$ & $28.8 \pm 2.75$ \\
Fish after chronic food restriction & $13.120 \pm 1.761$ & $0.087 \pm 0.0117$ & $33379 \pm 2022$ & $26 \pm 3.13$ \\
\hline
\end{tabular}

Data expressed as mean \pm SEM. Kruskal-Wallis followed by Dunn's post hoc test. Distance traveled $(K=21.44 ; p=0.0003)$, mean speed $(K=16.57 ; p=0.0023)$, absolute turn angle $(K=4.609 ; p=0.3298)$, and rotations $(K=7.959 ; p=0.0931)$. Significant effects are given in bold

Table 6 Number of crossings of zebrafish exposed to different forms of food deprivation stress

\begin{tabular}{llc}
\hline Substance & \multicolumn{2}{l}{ Number of crossings } \\
\cline { 2 - 3 } & $0-150 \mathrm{~s}$ (before substance influx) & $151-300 \mathrm{~s}$ (during substance influx) \\
\hline Control & $18.6 \pm 4.1$ & $31.11 \pm 6.85$ \\
$\mathrm{pH} 3$ & $20.5 \pm 4.23$ & $\mathbf{1 0} \pm \mathbf{2 . 9 7}$ \\
Fish in a normal nutritional status & $27.75 \pm 4.51$ & $23 \pm 3.27$ \\
Fish in acute fasting & $32.87 \pm 3.875$ & $32.7 \pm 4.91$ \\
Fish in chronic food restriction & $28.25 \pm 4.15$ & $27.5 \pm 4.85$ \\
\hline
\end{tabular}

Data expressed as mean \pm SEM. Data expressed as mean \pm SEM. Kruskal-Wallis followed by Dunn's post hoc test. Number of crossings $151-300 \mathrm{~s}$ (during substance influx) $(K=11.91 ; p=0.0180)$. Significant effect is given in bold physically stressed fish and by water from acutely fasted fish (disturbance chemical cues). However, the disturbance chemical cues released by a conspecific fish in visual contact with a predator did not elicit any response in terms of evasion or permanency.

The protocol and apparatus for this chemotactic preference test were first validated in an assessment of fish aversion to anesthetics and drugs (Readman et al. 2013; Abreu et al. 2016). We demonstrated that $\mathrm{pH} 3$ decreases the distance and mean speed, effects that had not been previously observed (Abreu et al. 2016), possibly the highest number of experimental groups in relation to this study and to detect a difference there is the need for a stronger effect. The aversive behavioral (avoidance or attraction) paradigm has been used to determine aversive experiences with tests using aversion measures, such as the percentage of time spent in conditioned or clear water. These behaviors are simple and objective measures that are easily quantifiable using fish models for preference or avoidance (Pelkowski et al. 2011). Thus, our methodology was reliable in the detection of fish evasive reactions to chemical stimuli.

Both aversion and permanency responses present intriguing results. We hypothesized that water from 
physically and chemically stressed fish and fish experiencing acute fasting would elicit an avoidance behavior in conspecifics because the information is direct. In fact, physical and chemical stress and acute fasting information did not need a specific context or lead to the release of a greater amount of the cue. The communication of the stressful situation has already been described in fish (Toa et al. 2004; Barcellos et al. 2011; Oliveira et al. 2013). Thus, physical and chemical stresses were communicated chemically in the water and were able to stress the fish in the apparatus. It is known that the simple introduction of water from stressed fish (sender) is capable of eliciting a complete stress response in the receiver fish, generalizing the stress response (cortisol increase) to all fish reared in tanks in a recirculating system (Barcellos et al. 2011).

We hypothesized that visual contact with a predator was not detected as an aversive stimulus because numerous predators use prey movement as a visual key to locate the prey and attack (Lima and Dill 1990; Burrows 1994; Burrows and Gibson 1995). Because the predator was not in the same aquarium as the test fish, an effective attack could not occur, and prey did not perceive the situation as life threatening.

Fasting induces change in some aspects of fish metabolism and endocrinology (Barcellos et al. 2010; Rossi et al. 2015), and production and reaction to alarm substances (McCormick and Larson 2008; Barreto et al. 2012). The mobilization of energy reserves from carbohydrates, lipids, or proteins could produce some metabolites that are excreted into the water (Jayaram and Beamish 1992; Lauff and Wood 1996; Wilkie 2002). Fasting promotes the release of the secretogranin II (SGII) precursor, which acts in neuroendocrine cells to stimulate the release of luteinizing hormone and increase locomotor behaviors in fish (Trudeau et al. 2012). Conversely, in chronic fasting, increased utilization of select tissue fatty acids in liver and muscle, increased plasma triglycerides, and decreased liver glucose and glycogen are observed (Pujante et al. 2015). However, chronic fasting trout did not significantly affect protein catabolism in peripheral tissues, indicated by reductions in the level of serum amino acids (Baumgarner and Cooper 2012). In addition, chronic fasting significantly increased pituitary GH expression, contrary to stress, which suppresses this axis (GH) (Malandrakis et al. 2016), suggesting that fish easily adjust their metabolism under situations characterized by chronic fasting. Furthermore, cortisol plays a crucial role in this fasting-induced energy mobilization (Wendelaar Bonga 1997; Mommsen et al. 1999) and is excreted to water via urine, bile (Vermeirssen and Scott 1996), and feces (Turner et al. 2003). Thus, it is plausible that fasted fish release chemical cues that are interpreted by conspecifics as threatening, unsafe, and/or undesirable situations.
Despite the ecological relevance of chemical communication of risk or stressful situations among fish, we found that an isolated fish without any specific context did not react to the majority of the classical chemical cues, especially those related to predator-prey relationships. Our data reinforced the hypothesis that fish use a combination of different information and the context of the situation to determine their evasion strategy.

Acknowledgments This study was approved by the Ethics Committee on Animal Use (CEUA) of the University of Passo Fundo (UPF), registration 29/2014, meeting the guidelines of the National Council of Animal Experimentation Control (CONCEA). The study was funded by the Universidade de Passo Fundo, and CNPq L.J.G.B. and R.E.B. hold CNPq research fellowships (301992/2014-2 and 302719/2013-0, respectively). ANYmaze ${ }^{\circledR}$ software (Stoelting, Co, USA) provided this software for behavioral analysis. The funders had no role in study design, data collection and analysis, decision to publish, or preparation of the manuscript.

\section{Compliance with ethical standards}

Conflict of interest The authors declare no conflicts of interest.

\section{References}

Abreu MS, Giacomini AC, Gusso D, Rosa JG, Koakoski G et al (2016) Acute exposure to waterborne psychoactive drugs attract zebrafish. Comp Biochem Physiol C Toxicol Pharmacol 179:37-43

Alsop D, Vijayan M (2009) The zebrafish stress axis: molecular fallout from the teleost specific genome duplication event. Gen Comp Endocrinol 161:62-66

Barbazuk WB, Korf I, Kadavi C, Heyen J, Tate S et al (2000) The synthetic relationship of the zebrafish and human genomes. Genome Res 10:1351-1358

Barcellos LJG, Marqueze A, Trapp M, Quevedo RM, Ferreira D (2010) The effects of fasting on cortisol, blood glucose and liver and muscle glycogen in adult jundiá Rhamdia quelen. Aquaculture 300:231-236

Barcellos LJG, Volpato GL, Barreto RE, Coldebella I, Ferreira D (2011) Chemical communication of handling stress in fish. Phys Behav 103:372-375

Barcellos LJG, Koakoski G, da Rosa JGS, Ferreira D, Barreto RE, Giaquinto PC, Volpato GL (2014) Chemical communication of predation risk in zebrafish does not depend on cortisol increase. Sci Rep 4:5076

Barreto RE, Barbosa A, Giassi ACC, Hoffmann A (2010) The 'club' cell and behavioural and physiological responses to chemical alarm cues in the Nile tilapia. Mar Fresh Behav Physiol 43:75-81

Barreto RE, Barbosa-Junior A, Hoffmann A (2012) Ventilatory responses to skin extract in catfish. Aquatic Biol 15:205-214

Baumgarner BL, Cooper BR (2012) Evaluation of a tandem gas chromatography/time-of-flight mass spectrometry metabolomics platform as a single method to investigate the effect of starvation on whole-animal metabolism in rainbow trout (Oncorhynchus mykiss). J Exp Biol 215:1627-1632

Brown C, Braithwaite VA (2005) Effects of predation pressure on the cognitive ability of the poeciliid Brachyraphis episcopi. Behav Ecol 16:482-487 
Burrows MT (1994) An optimal foraging and migration model for juvenile plaice. Evol Ecol 8:125-149

Burrows MT, Gibson RN (1995) The effects of food, predation risk and endogenous rhythmicity on the behaviour of juvenile plaice, Pleuronectes platessaL. Anim Behav 50:41-52

Chivers DP, Smith JF (1998) Chemical alarm signaling in aquatic predator-prey systems: a review and prospectus. Ecoscience 5:338-352

Egan R, Bergner CL, Hart PC, Cachat JM et al (2009) Understanding behavioral and physiological phenotypes of stress and anxiety in zebrafish. Behav Brain Res 205:38-44

Howe K, Clark MD, Torroja CF, Torrance J, Berthelot C et al (2013) The zebrafish reference genome sequence and its relationship to the human genome. Nature 496:498-505

Hussain A, Saraiva LR, Ferrero DM, Ahuja G, Krishna VS, Liberles SD, Korsching SI (2013) High-affinity olfactory receptor for the death-associated odor cadaverine. Proc Natl Acad Sci 110:19579-19584

Jayaram MG, Beamish FWH (1992) Influence of dietary protein and lipid on nitrogen and energy losses in lake trout, Salvelinus namaycush. Can J Fish Aquat Sci 49:2267-2272

Jordão LC, Volpato GL (2000) Chemical transfer of warning information in non-injured fish. Behavior 137:681-690

Korpi NL, Wisenden BD (2001) Learned recognition of novel predator odour by zebra danio, Danio rerio, following time-shifted presentation of alarm cue and predator odour. Environ Biol Fishes 61:205-211

Lauff RF, Wood CM (1996) Respiratory gas exchange, nitrogenous waste excretion, and fuel usage during starvation in juvenile rainbow trout, Oncorhynchus mykiss. J Comp Physiol B 165:542-551

Lima SL, Dill LM (1990) Behavioral decisions made under the risk of predation: a review and prospectus. Can J Zool 68:619-640

Malandrakis EE, Dadali O, Golomazou E, Kavouras M, Dailianis S, Chadio S, Exadactylos A, Panagiotaki P (2016) DNA damage and differential gene expression associated with physical stress in gilthead seabream (Sparus aurata). Gen Comp Endocrinol 236:98-104

McCormick MI, Larson JK (2008) Effect of hunger on the response to, and the production of, chemical alarm cues in a coral reef fish. Anim Behav 75:1973-1980

Mommsen TP, Vijayan MM, Moon TW (1999) Cortisol in teleosts: dynamics, mechanisms of action, and metabolic regulation. Rev Fish Biol Fisher 9:211-268

Mueller T, Vernier P, Wullimann MF (2004) The adult central nervous cholinergic system of a neurogenetic model animal, the zebrafish Danio rerio. Brain Res 1011:156-169

Oliveira TA, Koakoski G, Kreutz LC, Ferreira D, da Rosa JGS et al (2013) Alcohol impairs predation risk response and communication in zebrafish. PLoS One 8:e75780

Pelkowski SD, Kapoor M, Richendrfer HA, Wang X, Colwill RM et al (2011) A novel high-throughput imaging system for automated analyses of avoidance behavior in zebrafish larvae. Behav Brain Res 223:135-144

Pfeiffer W, Lamour D (1976) Effect of alarm substance on the heart rate in Phoxinus phoxinus (L.) (Cyprinidae, Ostariophysi, Pisces). Rev Suisse Zool 83:861-873

Pujante IM, Martos-Sitcha JA, Moyano FJ, Ruiz-Jarabo I, MartínezRodríguez G, Mancera JM (2015) Starving/re-feeding processes induce metabolic modifications in thick-lipped grey mullet (Chelon labrosus, Risso 1827). Comp Biochem Physiol B 180:57-67

Readman GD, Owen SF, Murrell TG (2013) Knowles. Do fish perceive anaesthetics as aversive? PLoS ONE 8:e73773

Rehnberg BG, Schreck CB (1987) Chemosensory detection of predators by coho salmon (Oncorhynchus kisutch)-behavioral reaction and the physiological stress response. Can J Zool $65: 481-485$

Rehnberg BG, Smith RJF, Sloley BD (1987) The reaction of pearl dace (Pisces, Cyprinidae) to alarm substance time-course of behavior, brain amines, and stress physiology. Can J Zool 65:2916-2921

Rossi A, Cazenave J, Bacchetta C, Campana M, Parma MJ (2015) Physiological and metabolic adjustments of Hoplosternum littorale (Teleostei, Callichthyidae) during starvation. Ecol Indic $56: 161-170$

Sabet SS, Neo YY, Slabbekoorn H (2015) The effect of temporal variation in sound exposure on swimming and foraging behaviour of captive zebrafish. Anim Behav 107:49-60

Sanches FHC, Miyai CA, Pinho-Neto CF, Barreto RE (2015) Stress responses to chemical alarm cues in Nile tilapia. Physiol Behav 149:8-13

Schwarze S, Bleckmann H, Schluessel V (2013) Avoidance conditioning in bamboo sharks (Chiloscyllium griseum and C. punctatum): behavioral and neuroanatomical aspects. J Comp Physiol A 199:843-856

Toa DG, Afonso LOB, Iwama GK (2004) Stress response of juvenile rainbow trout (Oncorhynchus mykiss) to chemical cues released from stressed conspecifics. Fish Physiol Biochem 30:103-108

Trudeau VL, Martyniuk CJ, Zhao E, Hu H, Volkoff H, Decatur WA, Basak A (2012) Is secretoneurin a new hormone? Gen Comp Endocrinol 175:10-18

Turner JW, Nemeth R, Rogers C (2003) Measurement of fecal glucocorticoids in parrot fishes to assess stress. Gen Comp Endocrinol 133:341-352

Vermeirssen ELM, Scott AP (1996) Excretion of free and conjugated steroids in rainbow trout (Oncorhynchus mykiss): evidence for branchial excretion of the maturation-inducing steroid, 17,20b-dihydroxy-4-pregnen-3-one. Gen Comp Endocrinol 101:180-194

Wendelaar Bonga SE (1997) The stress response in fish. Physiol Rev 77:591-625

Wilkie MP (2002) Ammonia excretion and urea handling by fish gills: present understanding and future research challenges. J Exp Zool 293:284-301 